\title{
COMPARISON OF SELECTED PARAMETRIC METHODS FOR PREDICTION OF INLAND WATERWAYS SHIP HULL RESISTANCE IN TOWING TANK TEST
}

\author{
Artur Karczewski \\ Janusz Kozak \\ Gdańsk University of Technology, Poland
}

\begin{abstract}
In the paper selected approximate methods for calculation of inland waterways ship resistance and their verification by towing tests, compared on the example of a small urban ferry, are presented. The test results are made for both the bare hull and the hull with appendages (skeg, azimuthal propeller). Significant differences between results of the theoretical methods and experimental ones, especially in the case of the model with skegs and propulsion, are pointed out. The purposefulness of using several parametric methods and the use of average results at the preliminary design stage were also discussed.
\end{abstract}

Keywords: ship resistance, inland waterways

\section{INTRODUCTION}

The ship design is a difficult, multi-stage process. Its typical structure is illustrated by Evans spiral [1] [2]. This is like a multi-flavoured pizza, where each triangle is only one part of a whole project, but composed of other parts as well. According to Michalski [2], the first step of such project is a parametric design phase. It identifies ship's parameters which determine the qualities of the whole project. One of the important actions in this design stage is proper prediction of the hull resistance. This usually is based on approximate calculation methods. Then the results are verified based on experiments in the towing tank. The parametric formulas are often useful only for a given ship type and hull arrangement, and for a set of its main parameters. The results of such calculations should be considered approximate. However the obtained data are used for defining the initial characteristics of the ship's propulsion system. They also serve as a starting point for experimental test. Forecasts based on experimental model studies are more accurate. They can be used to verify the design and determine a direction of possible modifications. The aim of these studies was verification of known parametric methods for resistance estimation, which could be used in the first design phase, as well as the defining of appropriate formulas which are easily adopted for PC without a high computing power. It is very important, especially for small ships, that such methods are not expensive. In this case the total price of project cannot be too high because building cost of a small ship is relatively low.

\section{PROJECT}

The project in question is the ship "Motława II" which should replace the existing ferry 'Motława' being in service since 1987. The new ship should be capable of meeting growing expectations of the passengers and crews and following today EU regulations. Design work on the 'Motława II' project 
started in March 2015 in the form of a collaboration between the National Maritime Museum (NMM) and the Gdansk University of Technology (PG).

The main requirements for the design were as follows:

- type of ship: a passenger urban ferry to be operated on the route between the Main City of Gdańsk and the Ołowianka Island, as the NMM has its buildings on both banks of the river;

- main parameters: hull length - 12,0m, beam - 5,0m, number of passengers: 36 persons, crew: 3 persons;

- $\quad$ structural material: steel;

- equal forward and backward manoeuvring properties.

As a result of the design process containing the elements of optimization [3] the shape of the hull was developed. For this hull the resistance analysis was performed by using parametric methods and model tests.

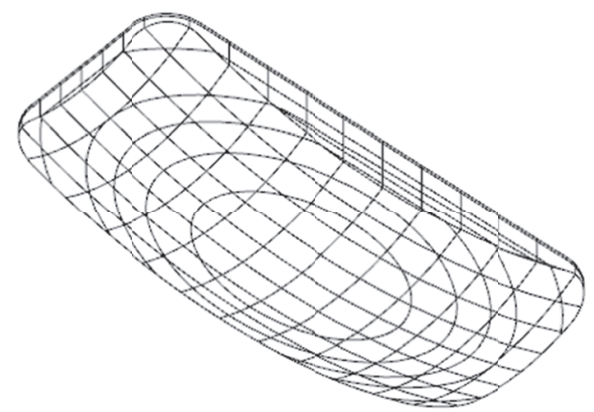

Fig. 1 Bare hull

The optimization showed that the best hull shape lies between a simple cuboid (highest stability) and a part of spheroid (lowest resistance). The new bottom shape was a part of spheroid suitable for changing its longitudinal and transverse curvatures [3].

Because the first study in the towing tank showed that the bare hull model was rather not able to keep a stable course and good manoeuvrability, the correction of hull shape was necessary. This problem was solved by installing skegs. In this case an estimate of resistance for the hull with appendages like skegs and azimuth thruster has been made.

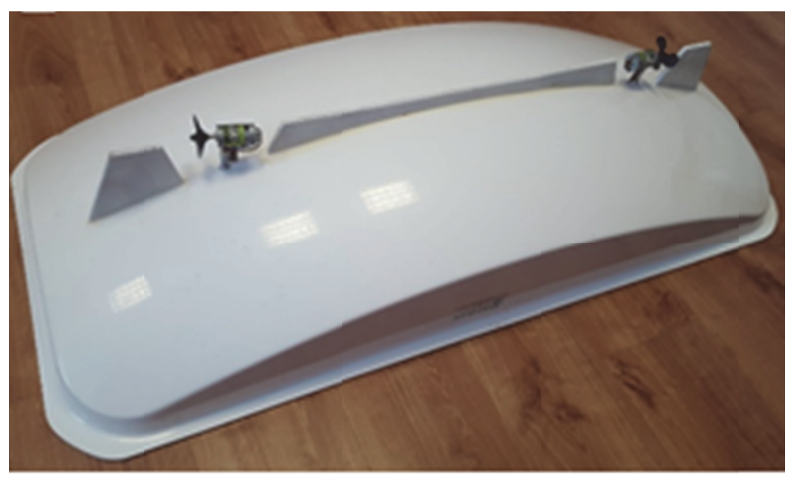

Fig. 2 The final version of 1:10 scale model with skegs and azimuth thruster.
Based on the made assumptions, the classification design project of the ship "Motława II" was developed.

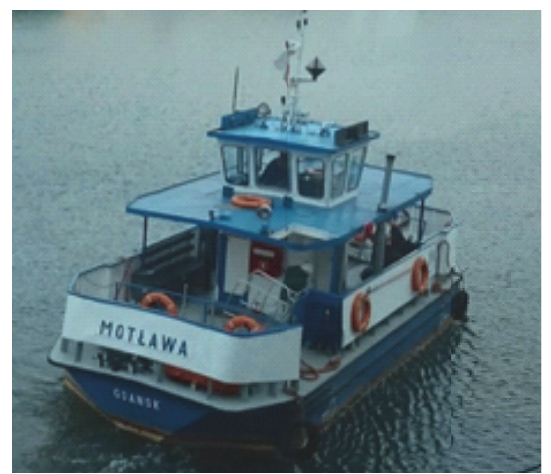

Fig. 3 The ship in operation since 1987

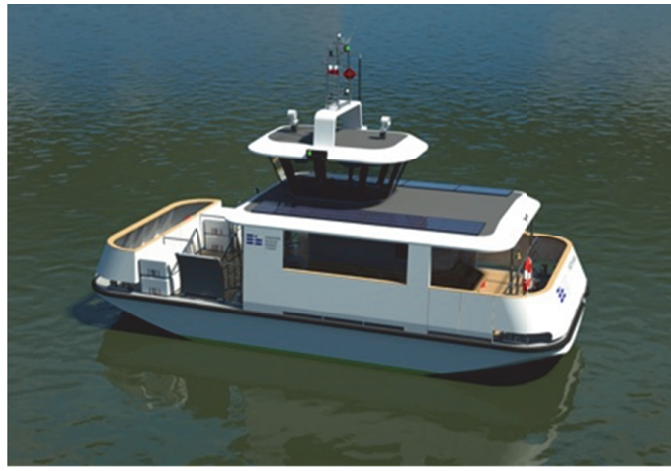

Fig. 4 Visualization of the new ferry

\section{SELECTED APPROXIMATE METHODS}

To perform the first estimation of hull resistance the methods presented in the literature [4] [5] have been used. Uncomplicated structure of the formulas is easy to implement to calculation spreadsheet. The methods in question are based on a limited set of hull parameters. They are expressed by nonstructural models elaborated by approximating the set of results of many towing tests.

\section{WRÓBLEWSKA - SIROTINA METHOD}

The total resistance of ship, $R_{T(W-S)}[\mathrm{kN}]$, acc. Wróblewska Sirotina method (W-S), is calculated by using the following equation:

$\left.\boldsymbol{R}_{T(W-S}\right)=0.1295 \cdot\left(48\left(\frac{v}{\sqrt{g \sqrt[3]{V}}}\right)^{2}-29\left(\frac{v}{\sqrt{g \sqrt[3]{V}}}\right)+5,9\right) \frac{B^{2} \cdot T \cdot \delta^{2}}{\left(\frac{B}{T}\right)^{0.2}}$

where:
$v$ - ship speed $[\mathrm{m} / \mathrm{s}]$;
$V$ - volumetric displacement $\left[\mathrm{m}^{3}\right]$;
$\delta$ - ship hull block coefficient [-]; 
$B$ - ship breadth $[\mathrm{m}]$;

$T$ - ship draught $[\mathrm{m}]$;

$g-9,81\left[\mathrm{~m} / \mathrm{s}^{2}\right]$.

\section{ZWANKOW METHOD}

The total resistance of ship, $R_{T(Z)}[\mathrm{kN}]$, acc. Zwankow method $(\mathrm{Z})$, is calculated by using the following equation:

$R_{T(Z)}=9,81 \cdot 10^{-3}\left(0.17 \cdot \Omega \cdot v^{1.825}+\delta \cdot A_{M} \frac{17.7 \delta^{2.5}}{\left(\frac{L}{6 B}\right)^{3}+2} v^{1.7}+4 \frac{v}{\sqrt{g \cdot L}}\right)$

where:

$\Omega$ - wetted hull area $\left[\mathrm{m}^{2}\right]$

$A_{M}$ - midship area $\left[\mathrm{m}^{2}\right]$;

$L$ - ship length $[\mathrm{m}]$.

\section{LENINGRAD DESIGN OFFICE METHOD}

The total resistance of ship, $R_{T(L D O)}[\mathrm{kN}]$, acc. Leningrad Design Office method (LDO) is calculated by using the following equation:

$R_{T(L D O)}=9,81 \cdot 10^{-3}\left(0.17 \cdot \Omega \cdot v^{1.825}+1.45\left(24-\frac{L}{B}\right) \cdot \delta^{5 / 2} \cdot \frac{D \cdot v^{4}}{L^{2}}\right)$

where:

$D$ - ship displacement $[\mathrm{t}]$.

\section{TOWING TEST}

In the experimental study the laminated 1:10 scale model of the ferry "Motława II " was used. The study was conducted in the towing tank of Faculty of Ocean Engineering and Ship Technology, Gdansk University of Technology, in calm water for two cases, without trim.

The main parameters of the hull model 511 and the real vessel are given in Tab. 1:

Tab. 1 Main parameters of the model and the real ship

\begin{tabular}{|l|c|c|}
\hline \multicolumn{1}{|c|}{ PARAMETER } & MODEL & SHIP \\
\hline $\mathrm{L}$ - ship length $[\mathrm{m}]$ & 1.20 & 12.00 \\
\hline B - ship breadth $[\mathrm{m}]$ & 0.50 & 5.00 \\
\hline $\mathrm{L}_{\mathrm{WL}}-$ ship waterline length $[\mathrm{m}]$ & 1.047 & 10.47 \\
\hline $\mathrm{T}$ - ship draught $[\mathrm{m}]$ & 0.093 & 0.93 \\
\hline $\mathrm{V}-$ volumetric displacement $\left[\mathrm{m}^{3}\right]$ & 0.0231 & 23.12 \\
\hline$\Omega$ - wetted hull area $\left[\mathrm{m}^{2}\right]$ & 0.5053 & 50.53 \\
\hline
\end{tabular}

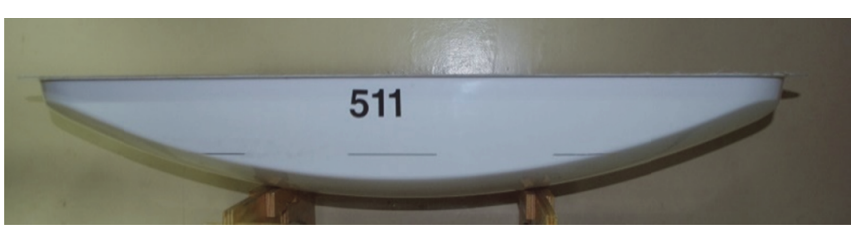

Fig. 5 Side view of the model without appendages

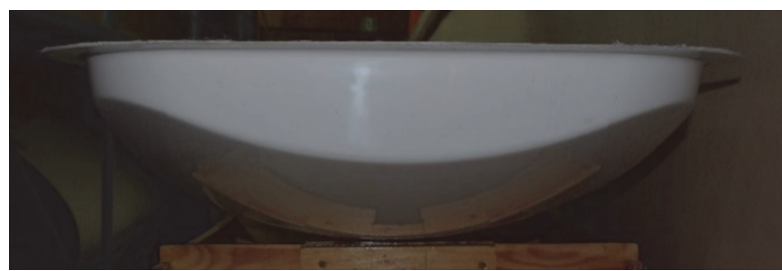

Fig. 6 Front view of the model without appendages

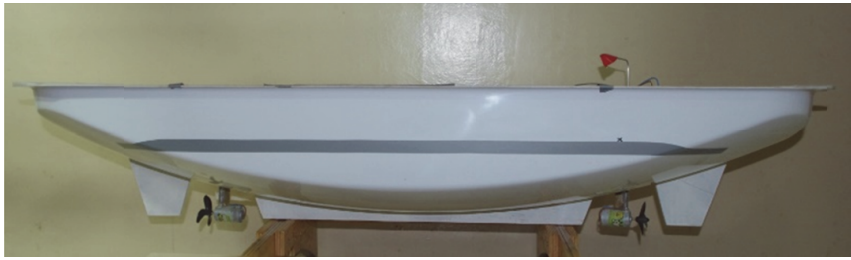

Fig. 7 Side view of the model with appendages

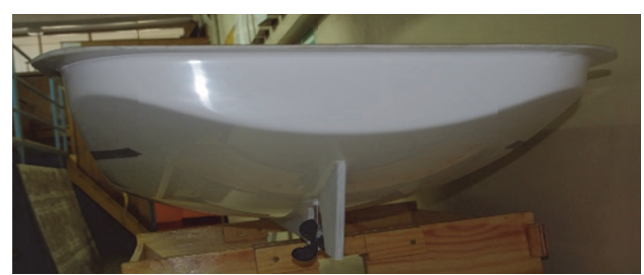

Fig. 8 Front view of the model with appendages

The measured total resistance of the model was recalculated to the scale of the actual ferry by using three-dimensional extrapolation based on the extended Froude method [6]. The total resistance coefficient was assumed to be typically composed of:

- friction resistance coefficient depending on the Reynolds number,

- residual resistance coefficient;

- pressure resistance coefficient taking into account the $k$ shape coefficient, which increases the level of friction resistance of both the ship and the model in relation to corresponding flat plates.

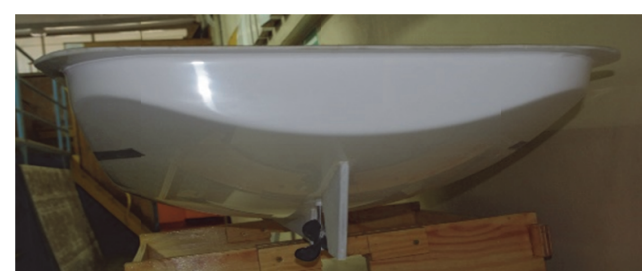

Fig. 9 Model without appendages during the test 


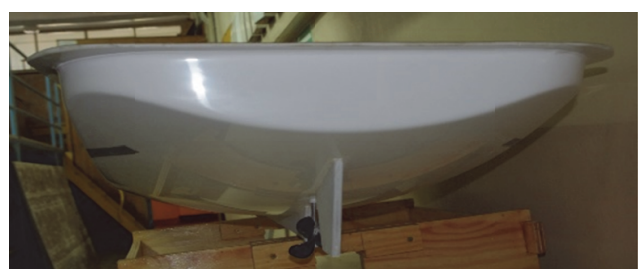

Fig. 10 Model with appendages during the test

\section{RESULTS}

The computational estimation of the hull resistance was determined by means of the three parametric methods : (W-S), (Z), (LDO).

The experimental study included measurement of resistance of the "Motława II " ferry 1:10 scale model in the speed range from 1.5 to $12.5 \mathrm{~km} / \mathrm{h}$. The study was conducted for two cases, without trim:

- Design conditions (A) for the model of bare hull, $R_{T(B)}$,

- Design conditions (B) for the model of hull with appendages, $R_{T(A)}$.

Based on the results of the studies, the forecast for the real ship's resistance was calculated. Results of both the studies are presented in the graphs.

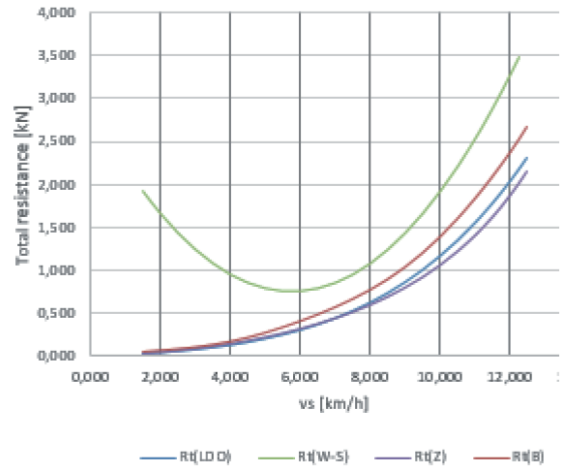

Fig. 11 Total resistance of bare hull

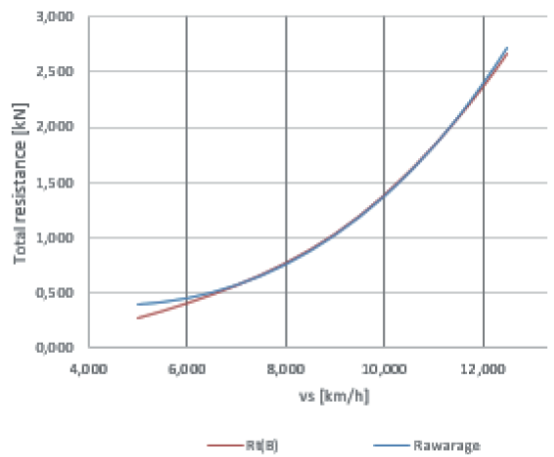

Fig. 12 Comparison of total resistance of bare hull

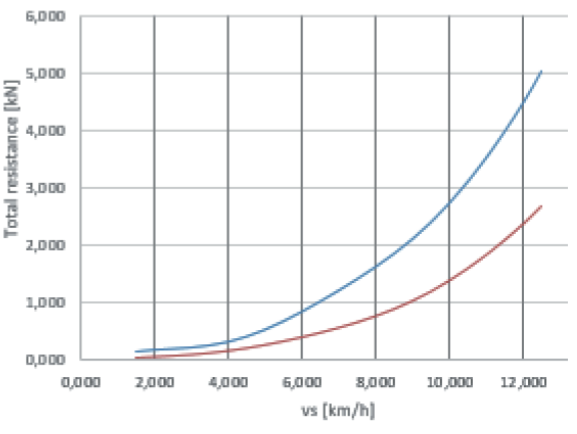

- RL(B) -RLA)

Fig. 13 Comparison of $\operatorname{Rt}(B)$ and $\operatorname{Rt}(A)$

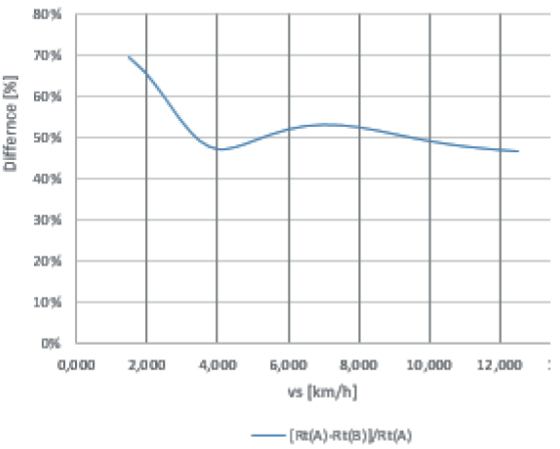

Fig. 14 Increase in the resistance [\%]

\section{CONCLUSION}

The results of approximate calculations performed by using parametric methods are close to those from the model tests of the hull without appendages. The adding of the skegs and azimuth thruster models resulted in a nearly double resistance and, as a consequence, also an increased demand for power. In the ship speed range between 3,5-:-12,5 [km/h] the increase in total resistance of the hull with appendages compared to that of the bare hull, is $\sim 50 \%$. The significant difference between the results obtained by using parametric methods and the results of model studies for the hull equipped with skegs and thrusters is typical since the approximate parametric methods do not take into account the appendages. Nevertheless, the nearly twofold rise in likely power demand $\left(\mathrm{R}_{\mathrm{t}} \mathrm{v}\right)$ following the mounting of skegs and azimuth thrusters, seems to be overestimated. According to the authors of this design, it results mostly from larger dimensions of the model azimuth thrusters than those resulting from the applied scale. Interesting is the situation in the case of taking the arithmetic mean from the parametric calculations, $\frac{1}{3}\left(R_{T(L D O)}+R_{T(W-S)}+R_{T(Z)}\right)$. It turns out that theoretical and experimental results for design condition are identical. However it should be remembered that the results has been achieved by using the W-S method. The applicability of this method is limited and the designed hull is formally beyond this range. 
The research shows that it is possible and desirable to use the simplified methods in the initial design phases. They allow very early and without effort and costs to determine the initial parameters of the propulsion system.

\section{ACKNOWLEDGMENTS}

The study was performed in the frame of the grant founded by the Provincial Fund for Environmental Protection and Water Management, Gdańsk, with the assistance of the National Maritime Museum in Gdańsk, which is the designated ship-owner of the new- designed ferry.

\section{BIBLIOGRAPHY}

1. A. Papanikolaou: Ship Design, Methodologies of Preliminary Design, London, Springer, 2014.

2. J. Michalski: Fundamentals of ship design theory ( in Polish), Gdańsk, Wydawnictwo Politechniki Gdańskiej, 2013.

3. A. Karczewski i Ł. Piątek: Reducing the Environmental Impact of the Public Water Transportation Systems by Parametric Design and Optimization of Vessels' Hulls. Study of the Gdańsk's Electric Passenger Ferry (2015-2016), in : Architecture for the Society of Knowledge, Warszawa, 2016.

4. J. Michalski: Methods useful for computer aiding the preliminary design process of inland waterways ships (in Polish), Gdańsk,Wydawnictwo Politechniki Gdańskiej, 2007.

5. A. Zborowski:Ship resistance ( in Polish), Gdańsk, Wydawnictwo Uczelniane Politechniki Gdańskiej, 1972.

6. M. Grygorowicz : Resistance tests of the ferry Motława II model in towing tank - results and their analysis ( in Polish), Politechnika Gdańska Wydział Oceanotechniki i Okrętownictwa, Gdańsk, 2016.

\section{CONTACT WITH THE AUTHORS}

Artur Karczewski

e-mail:artkarcz@pg.gda.pl

Janusz Kozak

e-mail:kozak@pg.gda.pl

Gdańsk University of Technology

11/12 Narutowicza St.

80 - 233 Gdańsk

Poland 